Quim. Nova, Vol. 36, No. 3, 474-479, 2013

\title{
AVALIAÇÃO DO CONHECIMENTO SOBRE PERIODICIDADE QUÍMICA EM UMA TURMA DE QUÍMICA GERAL DO ENSINO A DISTÂNCIA
}

\author{
Miguel de Araújo Medeiros* \\ Departamento de Ciências Biológicas, Universidade Federal do Tocantins, R. 07, Qd. 15, 77500-000 Porto Nacional - TO, Brasil
}

Recebido em 6/5/12; aceito em 1/10/12; publicado na web em 18/2/13

\begin{abstract}
ASSESSMENT OF KNOWLEDGE ON CHEMICAL PERIODICITY IN A DISTANCE-LEARNING GENERAL CHEMISTRY CLASS. This work describes the software Quiptabela, suggests a teaching activity, and analyses responses of general chemistry students from the Biological Sciences distance course at the Federal University of Tocantins. The software was described according to its educational potential, featuring the creation of dozens of charts or tables correlating physicochemical properties of the elements, being Brazilian, and free distribution. The teaching activities suggested analyzed students' ability to create and analyze tables and charts correlating the properties of chemical elements. Some $41 \%$ of students tested could define the term "periodic", but failed to use the concept to explain and differentiate changes in mass or atomic radius with the atomic number of elements.
\end{abstract}

Keywords: periodic properties; chemical periodicity; distance learning.

\section{INTRODUÇÃO}

A Tabela Periódica tem sido utilizada por educadores, possivelmente, da mesma maneira, desde o início do século XX, para o ensino das propriedades periódicas dos elementos. No entanto, o conceito de periodicidade é de importância fundamental para o ensino de química. ${ }^{1}$ A classificação periódica dos elementos permite o estudo de propriedades físicas e também químicas, mas o sucesso em sua aprendizagem pode ser alcançado quando o conteúdo for abordado em associação com conceitos de átomo e as teorias atômicas, que também são, assim como periodicidade dos elementos, abstratos e distantes da realidade dos estudantes. ${ }^{2}$

Acredita-se que o estudante, ao se envolver no estudo de periodicidade das propriedades dos elementos químicos, necessita exercitar algumas habilidades, assessorado pelo professor, tais como criação e interpretação de tabelas e gráficos e capacidade de formular modelos, algumas vezes, mentais, outras vezes explícitos. ${ }^{3}$ Para Fernandez e Marcondes ${ }^{4}$ e Driver e colaboradores,${ }^{5}$ trabalhar com a idealização e modelos é algo intrínseco do conhecimento científico e sem a sua utilização a Química fica restrita a observações e descrições de propriedades macroscópicas. ${ }^{4}$ Nesse contexto, o ato de ensinar e aprender Química ou, em especial, periodicidade química requer processos de teorização, construção e reconstrução de modelos que possibilitem a interpretação e explicação dos resultados pelos estudantes. ${ }^{6}$ Essas ações podem ser beneficiadas ao se utilizarem recursos computacionais, pois alguns softwares podem conter subsídios que estimulem a reflexão de maneira mais ampla. ${ }^{7}$

Nos dias atuais, não é mais possível separar a educação do meio onde o estudante está inserido, ou seja, cada vez mais se faz necessária a utilização de recursos computacionais no ensino. No entanto, é importante destacar que esse uso deve envolver o aluno, mostrando a ele que o computador é uma ferramenta que pode possibilitar a compreensão de alguns conceitos abstratos da Química, evitando a simples memorização do conceito. Partindo desse princípio e desenvolvendo roteiros para a utilização do computador e algum software associado, a aquisição de conhecimento pode ser facilitada e acelerada. É nesse contexto que foi elaborado o presente trabalho, cujo objetivo foi avaliar a aprendizagem do

*e-mail: mmedeiros@uft.edu.br conteúdo periodicidade das propriedades dos elementos químicos, em uma turma de Química Geral.

\section{PARTE EXPERIMENTAL}

O objetivo geral foi avaliar e relatar a aprendizagem do conteúdo periodicidade química dos elementos de 22 estudantes de Química Geral, de uma turma semipresencial de Ciências Biológicas da Universidade Federal do Tocantins (UFT). A disciplina de Química Geral teórica do curso de Ciências Biológicas, semipresencial, da UFT possui $80 \%$ de carga horária presencial e $20 \%$ a distância. As atividades de ensino avaliadas foram desenvolvidas durante o período não presencial da disciplina.

Os estudantes, ao receberem a proposta de atividade na plataforma Moodle, tiveram o período de $96 \mathrm{~h}$ para (i) conhecer e se acostumarem com o software utilizado e (ii) realizar e enviar a atividade $(48 \mathrm{~h})$. As questões da atividade só foram disponibilizadas aos estudantes após o período de $48 \mathrm{~h}$ iniciais. O professor da disciplina se disponibilizou por $16 \mathrm{~h}$ ( $4 \mathrm{~h}$ para sanar e auxiliar os estudantes na utilização do software, que era novidade para todos os alunos da disciplina; $12 \mathrm{~h}$ durante a realização das atividades, divididas em 4 períodos de $3 \mathrm{~h}$, cobrindo todos os períodos do dia - manhã, tarde e noite) para sanar dúvidas ou auxiliar os estudantes na realização das atividades. Após esta atividade, o histórico da classificação periódica dos elementos foi introduzido aos estudantes através das curvas de propriedades periódicas e aperiódicas criadas por eles mesmos. Em um terceiro momento, algumas aplicações e importâncias dos elementos químicos no cotidiano também foram introduzidas aos estudantes.

Para alcançar o objetivo geral deste trabalho, realizaram-se: (i) descrição do software educativo QuipTabela e (ii) sugestão de atividade e avaliação das respostas dos estudantes.

A estrutura da atividade de ensino, aplicada aos estudantes de Química Geral, foi elaborada pelo próprio professor da disciplina. Para a elaboração dessa atividade, o professor considerou uma proposta de Mortimer e Machado ${ }^{8}$ e Eichler e Del Pino ${ }^{9}$ para a abordagem do conteúdo. As questões que compõe a atividade de ensino são listadas a seguir.

1) Crie um gráfico com os valores de raio atômico em função do número atômico para todos os elementos da tabela periódica. Use um dos eixos para a variável independente e outro eixo para 
a variável dependente (salve um arquivo com a curva do gráfico). Observe esse gráfico e responda as seguintes questões: (a) como é a variação do raio atômico no decorrer do $2^{\circ}, 3^{\circ}$ e $4^{\circ}$ períodos da tabela periódica (com o aumento do número atômico)? (b) como é a variação do raio atômico no decorrer da $1^{\mathrm{a}}$ e da $2^{\mathrm{a}}$ coluna da tabela periódica? ${ }^{8}$

2) Crie um gráfico com os valores da massa atômica em função do número atômico para todos os elementos da tabela periódica. Use um dos eixos para a variável independente e outro eixo para a variável dependente (salve um arquivo com a curva do gráfico). Observe esse gráfico e responda as seguintes questões: (a) como é a variação da massa atômica no decorrer do $2^{\circ}, 3^{\circ}$ e $4^{\circ}$ períodos da tabela periódica (com o aumento do número atômico)? (b) como é a variação da massa atômica no decorrer da $1^{\mathrm{a}} \mathrm{e}$ da $2^{\mathrm{a}}$ coluna da tabela periódica? (c) compare o gráfico obtido nesta questão, com o obtido na questão anterior. Qual é a principal diferença entre as duas curvas? Explique.

3) (a) Para você, qual é o significado da palavra periódico? (b) Dê 2 exemplos de fenômenos naturais ou artificiais, que sejam periódicos (responda de maneira geral, excluindo situações envolvidas com periodicidade das propriedades dos elementos químicos) e 2 fenômenos que sejam não periódicos. (c) Qual das duas propriedades (raio ou massa atômica) pode ser considerada periódica em relação ao número atômico (se necessário, reveja os gráficos das questões 1 e 2)? (d) O que caracteriza essa propriedade como periódica?

4) (a) No gráfico da questão 1 , identifique os elementos químicos correspondentes aos 3 máximos da curva, no intervalo de número atômico de 1 a 25. (b) Eles pertencem a qual grupo da tabela periódica? (c) Verifique os outros máximos desse gráfico. A que grupo eles pertencem? O resultado observado já era esperado? Explique.

5) Anote o valor do número atômico dos 3 primeiros máximos da curva da questão 1. (a) Na forma de desenhos esquemáticos, crie modelos que representem esses átomos. (b) Quantos níveis eletrônicos há em cada um desses átomos? (c) Com base em seus modelos, qual é a ordem crescente dos raios atômicos para esses átomos? (d) Como você representaria (na forma de desenhos esquemáticos) os dois átomos que estão imediatamente após os átomos identificados nesta questão? (e) Esse resultado está de acordo com o gráfico obtido na questão 1 ?

6) (a) Qual(is) é(são) a(s) teoria(s) atômica(s) que consegue(m) explicar as observações realizadas nos itens anteriores? Explique.

Outra questão que poderia constar na atividade:

7) Sem verificar quais são os elementos correspondentes aos mínimos do gráfico da questão 1, responda: qual(is) deve(m) ser o(s) grupo(s) correspondente(s) aos mínimos, no gráfico da questão 1 ?

\section{RESULTADOS E DISCUSSÃO}

\section{Descrição do software educativo QuipTabela}

O software utilizado (Figura 1) está em português e permite visualizar e listar mais de 30 propriedades e informações sobre cada um dos elementos químicos. A partir da lista de propriedades físico-químicas, é possível criar dezenas de correlações entre essas propriedades, em tabelas e/ou gráficos.

Acredita-se que é de pouco proveito para o processo de ensino-aprendizagem a utilização de esquemas gráficos que simplesmente resumem o conhecimento, oferecendo apenas (i) o produto acabado para mera fixação/memorização e (ii) a construção de conceitos equivocados sobre o assunto. Para Maia e Justi, ${ }^{10}$ a utilização de modelos simplificados, e mesmo errados, pode dificultar a interligação de conceitos básicos na Química. É importante perceber que o conhecimento é fruto de uma aprendizagem e não apenas

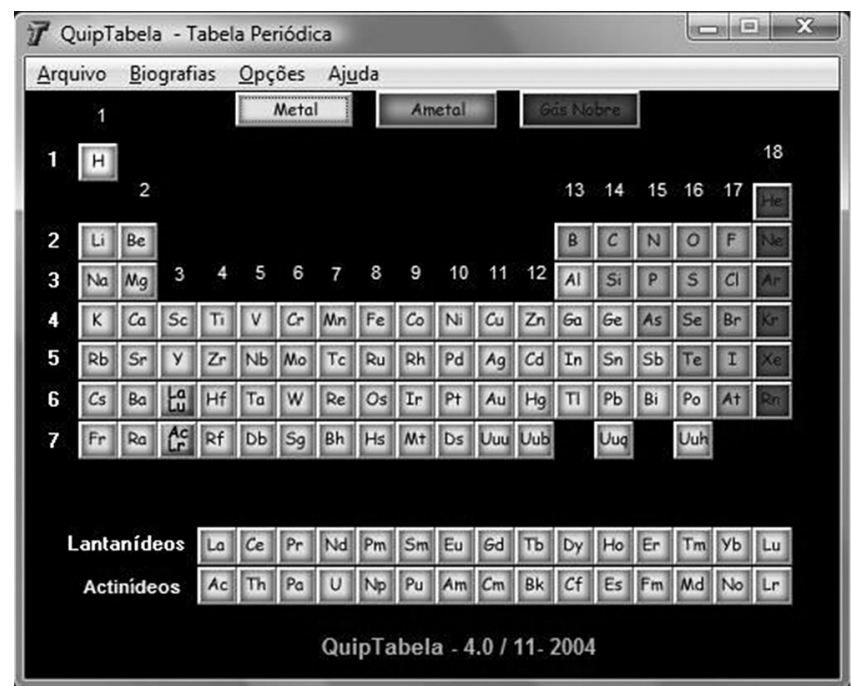

Figura 1. Tela inicial do programa QuipTabela

um produto acabado, ou melhor, ele é bastante dependente do caminho percorrido pelo estudante durante todo o processo de aprendizagem. Dessa maneira, a partir da criação e interpretação de tabelas e curvas de gráficos, os estudantes podem criar relações entre as propriedades físico-químicas dos elementos, entendendo como se dá a variação de uma propriedade em função da outra e não apenas observando um esquema gráfico, com setas indicativas, pronto para a memorização. Isso, possivelmente, pode ser alcançado utilizando o QuipTabela, que oferece seções ("Ordenação" e "Comparação") que tornam possível a correlação de propriedades, pois os elementos químicos podem ser ordenados de acordo com qualquer propriedade físico-química associada a ele ou ao átomo do seu isótopo mais comum (temperatura de fusão, de ebulição, densidade, condutividade térmica, resistividade elétrica, volume molar, calor específico, calor de fusão, massa atômica, eletronegatividade, energia de ionização, raio atômico, afinidade eletrônica e carga nuclear efetiva) disponibilizada no banco de dados do software. A presença de filtros que delimitam valores tornam as tabelas mais claras e objetivas, facilitando a comparação dos dados. A criação e análise de tabelas, pelos estudantes, possibilitam ao professor a realização de perguntas como: "qual é a dependência da propriedade listada em relação ao número atômico?"; "há alguma variação que se manifeste de maneira periódica?". ${ }^{9}$ Através dessas e de outras perguntas ("qual é a dependência da propriedade listada em relação à massa atômica?"; "há alguma semelhança entre esta dependência e a demonstrada para o número atômico?"; "qual é a relação entre a massa e o número atômico?") o professor poderá ter ciência da direção que o aprendiz está tomando em sua aprendizagem, podendo interferir, caso seja necessário, para melhor direcioná-lo rumo à aquisição do conhecimento desejado.

O software permite ainda a criação de dezenas de gráficos, que correlacionam todas as propriedades físico-químicas dos elementos, presentes em sua base de dados. Essa é uma característica desejada em um software deste tipo, pois é de conhecimento comum que a criação e análise de gráficos possibilitam (i) o desenvolvimento da habilidade de interpretação gráfica de dados, tão importante em diversas áreas do conhecimento e (ii) a melhor compreensão do conceito em estudo, pois as variações das propriedades ficam mais evidentes do que em uma simples tabela de dados.

O QuipTabela foi escolhido para a realização das atividades aqui propostas, pois se trata de um software com distribuição gratuita e que funciona em qualquer versão do sistema operacional Microsoft Windows. Além disso, o software está em língua portuguesa e permite 
a criação simples e rápida de tabelas e gráficos (quando comparada com a criação manual, utilizando, por exemplo, papel milimetrado), o que auxilia na comparação dos dados de propriedades físico-químicas dos elementos.

O software permite ainda a abordagem de fatos históricos referentes a cada elemento químico e também a cada grupo (família) da tabela periódica, mostrando características que revelam como os elementos foram listados na ordem em que se encontram atualmente. Em outras seções do software há descrições sobre a origem do elemento químico na natureza e algumas de suas aplicações. Outras funcionalidades menos expressivas podem auxiliar no ato de ensinar e aprender periodicidade das propriedades dos elementos químicos, tais como: (i) expansão do corpo da tabela periódica para a entrada dos elementos de transição interna e (ii) identificação dos elementos químicos, no próprio corpo da tabela periódica, através de estados físicos, configuração eletrônica, classe ou grupo.

\section{Sugestão da atividade e avaliação das respostas}

A atividade sobre periodicidade das propriedades físico-químicas dos elementos, proposta aos estudantes da turma de Química Geral, do curso de Ciências Biológicas à distância, da UFT, procurou trabalhar uma dificuldade de vários alunos do curso de graduação, presencial, desta mesma universidade, que é a criação e interpretação de gráficos e tabelas.

O desenvolvimento da atividade buscou (i) dar significado ao termo periódico, mostrando que fenômenos presentes no cotidiano também podem apresentar variação periódica; (ii) criar oportunidade para os estudantes interagirem com o conteúdo e desenvolverem a sua própria aprendizagem e (iii) utilização de recursos de informática como estratégia para consolidar o ensino à distância.

A análise das respostas, a cada uma das questões da atividade proposta, permitiu observar alguns problemas de aprendizagem do conteúdo.

\section{Questão 1}

Alguns estudantes (6 entre os 22 analisados) apresentaram dificuldade em criar o gráfico de raio em função do número atômico. As principais dificuldades foram em relacionar a propriedade independente com a propriedade dependente, ou seja, o raio atômico dependente do número atômico. No momento de interpretação da curva do gráfico, 2 desses estudantes apresentaram ideias incoerentes com o perfil da curva apresentada por eles. Esse resultado demonstra que os estudantes possuem algum conhecimento (prévio ou adquirido em materiais como livros didáticos ou páginas da internet) sobre a variação do raio atômico e que está distinto do que é observado nas curvas dos gráficos criados por eles.

Ao responderem as perguntas: "como é a variação do raio atômico no decorrer do segundo, do terceiro e do quarto período da tabela periódica?" e "como é a variação do raio atômico no decorrer da primeira e da segunda coluna da tabela periódica?", 16 estudantes responderam da maneira esperada, ou seja, o raio atômico diminui em um mesmo período, mas ao aumentar o número de camadas eletrônicas, o raio atômico aumenta. A citação de um estudante transcrita a seguir exemplifica as respostas dadas por esse grupo de alunos. ${ }^{1}$

"O raio atômico dos átomos diminui com o aumento do número atômico, pois a curva tá para baixo." "Ao mudar de linha, na tabela periódica, os elementos aumentam o raio atômico, pois está aumentando o número de camadas eletrônicas $(k, l, m, n . .$.$) e pelo gráfico, a gente vê um novo$ máximo." (Estudante L)
O trecho transcrito dá indícios de que o estudante consegue interpretar os dados apresentados no gráfico e ainda relacioná-los com a organização dos elementos na tabela periódica. Neste momento da abordagem do conteúdo, ainda não foi mencionado aos estudantes que a tabela periódica foi organizada, na forma em que se encontra, a partir das semelhanças periódicas em algumas propriedades, mas mesmo assim, o estudante consegue fazer alusão a essa ideia. Já 4 desses alunos conseguem relacionar a variação do raio atômico com algo periódico, citando essa ideia em suas respostas, observe.

"No decorrer do $2^{\circ}, 3^{\circ}$ e $4^{o}$ período da tabela periódica, o raio atômico aumenta. A gente vê isso através dos primeiros elementos de cada período, que são todos do grupo 1. Quando aumenta o número atômico, em um mesmo período, o raio diminui. Essas variações são periódicas, variam de período a período." (Estudante $\mathrm{J}$ )

Dentre os 6 estudantes que apresentaram dificuldade em criar o gráfico, 4 também tiveram dificuldades em interpretá-lo, pois as curvas se apresentam de maneira não usual. Como consequência, esses estudantes não forneceram respostas a respeito da variação do raio em função do número atômico, pois a análise se torna complexa.

\section{Questão 2}

Esta questão da atividade não foi resolvida por 3 estudantes da disciplina. Já os outros 19, criaram e interpretaram o gráfico da maneira esperada, ou seja, a massa atômica sofre uma elevação praticamente linear com o aumento do número atômico. Ao analisar o gráfico criado por cada estudante, observou-se que os mesmos 6 estudantes, que não souberam relacionar, em um gráfico, a dependência entre o raio e o número atômico, também não souberam criar a relação de dependência entre a massa e o número atômico. Pelo fato da massa sofrer uma variação praticamente linear com o aumento do número atômico, não houve desarmonia entre a curva esperada e a traçada, o que não prejudicou a análise da tendência. O trecho transcrito a seguir, exemplifica as respostas dos estudantes para as seguintes perguntas: "como é a variação da massa atômica no decorrer do segundo, do terceiro e do quarto período da tabela periódica?" e "como é a variação da massa atômica no decorrer da primeira e da segunda coluna da tabela periódica?”

"A massa atômica aumenta com o número atômico. Praticamente não tem oscilação nos valores ao olhar os períodos e grupos da tabela periódica." (Estudante A)

Um estudante, entre os 19 que responderam da maneira esperada, relacionou esse aumento praticamente linear da massa com propriedades nucleares dos átomos.

"A massa atômica aumenta, quando também se aumenta o número atômico e isso é esperado, pois o número de prótons e nêutrons também aumenta." (Estudante L)

O Estudante L, através do trecho transcrito anteriormente, demonstra a habilidade (esperada para todos os estudantes) em correlacionar o estudo da variação de propriedades físico-químicas dos elementos com conteúdos previamente estudados na disciplina (propriedades atômicas). Essa correlação entre conteúdos é de suma importância para o estudo de tais conteúdos, que estão intimamente relacionados.

Ao solicitar aos estudantes que comparassem as curvas dos gráficos obtidos nas Questões 1 e 2, constatou-se que 13 souberam diferenciar uma variação periódica (raio atômico) de uma não 
periódica (massa atômica), conforme é mostrado em uma resposta transcrita a seguir. Entretanto, esse resultado é diferente do esperado, pois 16 estudantes identificaram uma variação do raio atômico, que se reproduz (e seria periódica), na Questão 1. Isso mostra que 3 daqueles estudantes (os 16 que responderam a Questão 1, da maneira esperada) não sabem, realmente, identificar uma variação periódica através de uma curva de gráfico. O que leva à hipótese desses 3 estudantes terem copiado a resposta de alguma fonte de informação, sem a preocupação com a sua compreensão e relação com o gráfico traçado.

"O raio não varia como a massa, que aumenta com o crescimento do número atômico. A variação da massa do átomo não é periódica, mas a do raio atômico é." (Estudante $\mathrm{J}$ )

Os outros 9 estudantes da disciplina ficaram divididos em: os que não responderam ( 2 estudantes) e os que apresentaram dificuldade na comparação entre as duas curvas ou conflitos conceituais (7 estudantes). Desses estudantes, apenas um traçou as curvas corretamente, mas não soube compará-las, verificando se havia ou não um fenômeno periódico. Já os outros (6 estudantes), apresentaram uma dificuldade já discutida na questão 1 (problemas em relacionar, no gráfico, o raio atômico como dependente do número atômico, ou seja, y em função de x). Essa dificuldade, possivelmente acarretaria na análise não esperada entre as curvas de massa e raio em função do número atômico, como se pode perceber nos trechos transcritos a seguir.

"O raio atômico diminui com o aumento do número atômico, com exceção de alguns elementos. A massa atômica tende a aumentar com o número atômico.” (Estudante B)

"A massa dos átomos aumenta com o número atômico, na tabela periódica e o raio tem uma variação estranha." (Estudante $\mathrm{S}$ )

O Estudante $\mathrm{S}$, que traçou a curva do raio em função do número atômico de maneira não usual (Figura 2b), interpretou corretamente a curva desenhada, que não representa a variação esperada (Figura 2a) para esta propriedade. Já o Estudante B, descreveu uma situação incompatível até mesmo com a curva, que envolve o raio atômico e o número atômico, traçada por ele (Figura 2 b). Esse resultado demonstra que o Estudante B interpretou uma curva diferente daquela que ele forneceu como resposta (Figura 2b) ou, ainda, analisou o gráfico considerando a escala vertical como decrescente, em seu sentido ascendente.

\section{Questão 3}

Ao questionar os estudantes sobre o significado da palavra periódico, apenas um não respondeu. Todos os outros 21 , responderam se tratar de algo que se repete com regularidade, conforme se pode perceber nas respostas transcritas a seguir.

"Periódico é aquilo que se reproduz em intervalos iguais." (Estudante L)

\section{"Um fenômeno periódico é aquele que se inicia e termina} com repetição e regularidade.” (Estudante $\mathrm{A}$ )

"Para mim, a palavra periódico significa o mesmo que variação que se repete sempre.” (Estudante $\mathrm{U}$ )

Cada estudante citou pelo menos 2 exemplos de fenômenos periódicos, como era solicitado, num total de 53 citações. Nenhum dos exemplos fornecidos pelos estudantes fazia referência a fenômeno ou situação de ocorrência não periódica. Os exemplos mencionados estão sintetizados na Figura 3 e as quantidades estão representadas em percentagem.

Embora tenha sido solicitado aos estudantes para não citar propriedades atômicas, como exemplos de fenômeno ou situação periódica, $6 \%$ das respostas fizeram alusão à eletronegatividade $\mathrm{e}$ raio atômico, demonstrando falta de atenção de alguns estudantes ao enunciado da questão.

A copa do mundo de futebol foi a situação mais comum entre as respostas dos estudantes, representando $41 \%$ delas. Esse resultado é devido, possivelmente, à proximidade do evento ao período em que os estudantes responderam à questão ( $1^{\circ}$ semestre de 2010). Outros fenômenos e situações lembradas pelos estudantes foram as fases da lua, em relação aos dias do mês (19\%), as estações do ano, em relação aos meses (28\%) e os jogos olímpicos, em relação aos anos

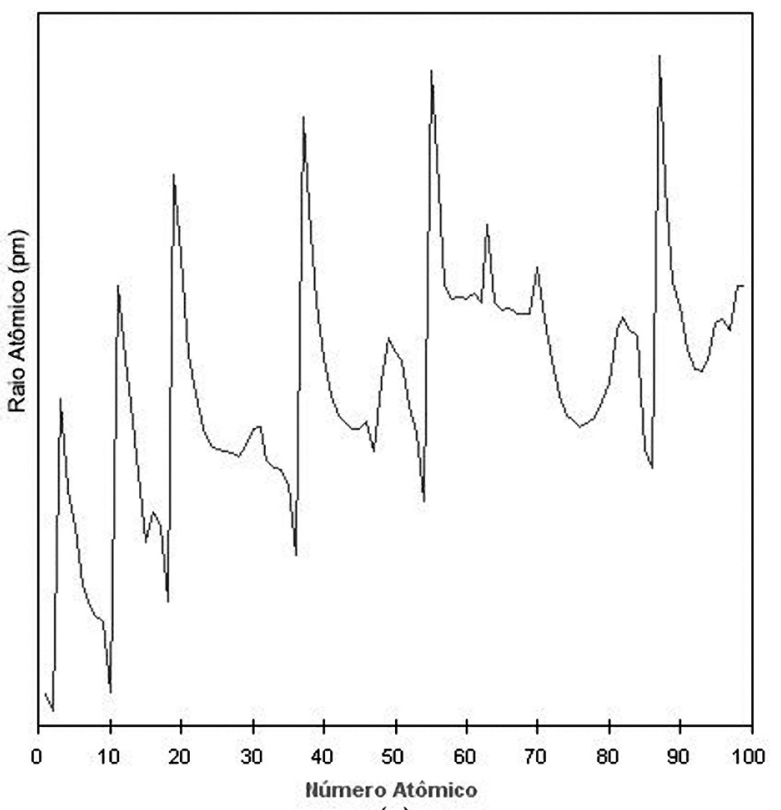

(a)

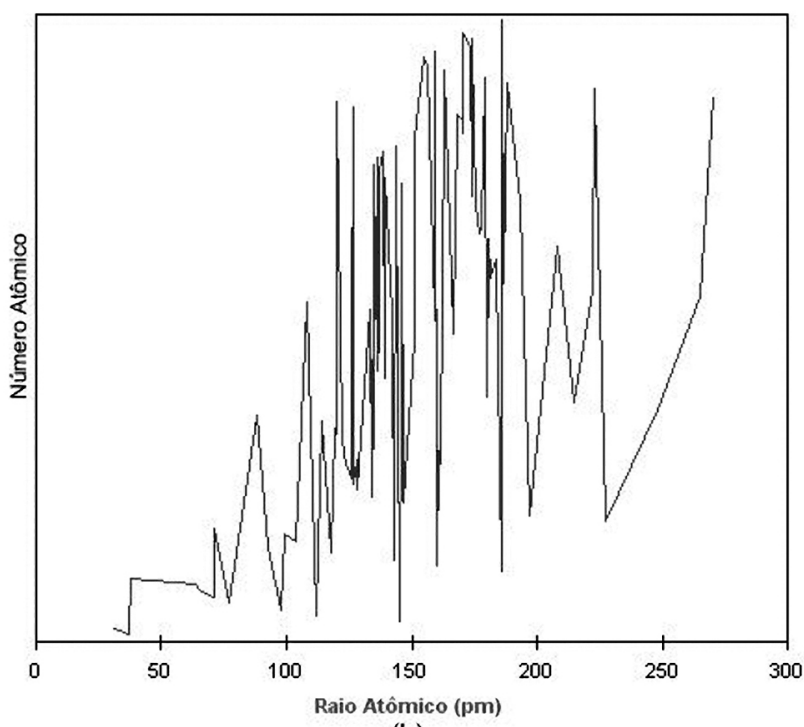

(b)

Figura 2. Curvas traçadas pelos estudantes. (a) Raio atômico em função do número atômico e (b) número atômico em função do raio atômico 


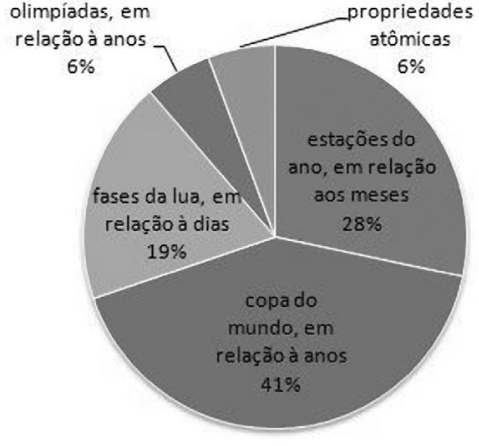

Figura 3. Exemplos de fenômenos ou situações consideradas periódicas, pelos estudantes

(6\% das respostas). Já os exemplos dos estudantes para fenômenos ou situações não periódicos foram bastante diversificados, num total de 44 citações. Alguns desses exemplos foram: acidente de carro, doenças, tempestades, ocorrência de terremotos e reprovação em disciplinas na faculdade, todos em relação a unidades de tempo (dias, meses e anos). Além de situações como essas, um exemplo curioso, porém relacionado, foi citado por um dos estudantes, observe o trecho transcrito a seguir.

"O movimento de uma mosca em busca de alimento representa um movimento que não é periódico, nem mesmo em relação a outra mosca.” (Estudante J)

Outros itens, inclusos na questão 3, versaram a respeito de qual das duas propriedades (massa ou raio atômico) poderia ser periódica em relação ao número atômico e o porquê. Entre os 22 estudantes, apenas 14 responderam da maneira esperada para o raio atômico (variação periódica) e para a massa atômica (variação não periódica). Já para 5 estudantes, a variação da massa atômica está relacionada com um evento periódico, veja o trecho transcrito a seguir. Esse resultado evidencia um problema na aprendizagem do conteúdo: os estudantes não conseguiram relacionar o conhecimento geral sobre periodicidade com as propriedades atômicas apresentadas nos gráficos das questões 1 e 2 (busca mental de conceitos prévios e interpretação de gráficos), embora todos os 22 estudantes tenham indicado corretamente fenômenos ou situações que variam de maneira periódicas. Os outros 3 estudantes não responderam esse item da questão 3.

"A massa atômica cresce periodicamente com o aumento do número atômico, pois ela está constantemente aumentando.” (Estudante W)

\section{Questão 4}

Os estudantes ao responderem à questão 4 , que trata da identificação dos elementos químicos correspondentes aos máximos da curva de raio atômico dependente do número atômico, se dividiram em dois grupos, (i) os que responderam da maneira esperada e (ii) aqueles que simplesmente não forneceram nenhuma resposta. Os estudantes que responderam à questão 4 foram os mesmos que responderam à letra c da questão 3, ou seja, 14 estudantes. As respostas destes estudantes para os itens "a" e "b" foram lítio, sódio e potássio, associando-os ao grupo 1 da classificação periódica. A justificativa destes estudantes para a escolha destes elementos foi que os elementos deste grupo apresentam menos elétrons na camada de valência, quando comparados aos outros elementos, o que propicia a eles menor força de atração entre o núcleo e a última camada eletrônica do átomo. Estes estudantes também foram capazes de prever os outros elementos do grupo 1 (rubídio, césio e frâncio), a partir da interpretação do gráfico. O trecho transcrito a seguir exemplifica esse pensamento comum dos estudantes.

"Quanto maior o número de camadas, maior será o raio atômico. E quanto menor for a quantidade de elétrons, para elementos que se encontram na mesma linha da tabela periódica, menor será a força de atração do núcleo do átomo com a última camada de elétrons, logo, maior será o raio atômico.” (Estudante L)

Os outros 8 estudantes, que não esperavam o resultado, não souberam ou simplesmente não quiseram responder, deixaram a questão sem resposta. Esse resultado pode sugerir que uma parcela importante dos estudantes apresenta dificuldade em compreender, em nível microscópico, o conteúdo. Segundo Johnstone, ${ }^{11}$ essa é uma importante fraqueza da Química (alunos tentarem aprender em nível microscópico), mas também pode ser o grande diferencial, quando tratada como uma atividade para desenvolvimento intelectual. Acreditamos que o professor deve valorizar, sempre que possível, a relação entre o macro e o microscópico, pois dessa maneira o estudante saberá ou terá maior facilidade em compreender alguns fenômenos físico-químicos.

\section{Questão 5}

Embora a questão 5 seja bastante semelhante à questão 4, foi solicitado aos estudantes que fizessem desenhos esquemáticos para representar os átomos aos quais eles associam aos três máximos do gráfico de raio atômico dependente do número atômico. Esta questão foi respondida por apenas 11 estudantes, que se dividiram entre: (i) 9 estudantes que forneceram desenhos para os átomos de lítio, sódio e potássio (os três primeiros elementos do $1^{\circ}$ grupo da classificação periódica), que se encaixam no modelo atômico proposto por Niels Bohr, em 1913 (Figura 4) e (ii) 2 estudantes que representaram apenas os elétrons de valência de cada um dos átomos, em torno de seus símbolos químicos (estrutura eletrônica de Lewis).
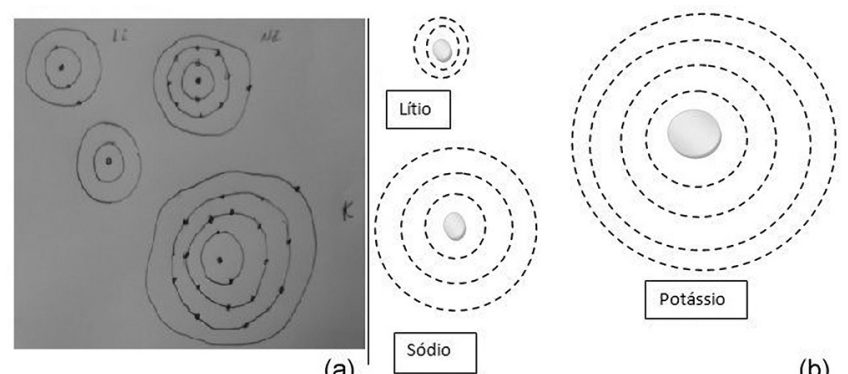

(b)

Figura 4. Representações, criadas por estudantes, para os átomos de lítio, sódio e potássio. (a) Estudante J. (b) Estudante L

A representação dos átomos de metais alcalinos (Figura 4a) é o resumo das representações de 8 estudantes, que exibiram o núcleo atômico e os elétrons em torno, como em uma órbita circular, evidenciando todos os elétrons. Já a representação do estudante L (Figura 4b) evidencia apenas o núcleo atômico, com órbitas circulares, no entanto, os elétrons não são apresentados. Em ambas as representações, é mantida uma relação crescente entre os raios atômicos, como era de se esperar.

Outro item da questão 5 solicitou aos estudantes que desenhassem os átomos subsequentes ao potássio. Todos os 11 estudantes forneceram algum tipo de resposta (as representações dos átomos foram semelhantes às exibidas na Figura 4, para Li, Na e K). Entretanto, apenas 8 estudantes afirmaram que o resultado estava de acordo com o observado no gráfico da Questão 1, como o trecho a seguir demonstra. 
"Os elementos da primeira coluna da tabela periódica são os que apresentam os maiores raios atômicos, pois eles apresentam menor número de elétrons na última camada, quando comparados com os outros elementos da mesma linha da tabela. E isso também pode ser notado no gráfico da questão 1, pois todos os picos máximos são elementos da primeira coluna da tabela periódica." (Estudante L)

Questão 6

Os estudantes, ao serem questionados sobre qual teoria atômica conseguiria abranger os fatos observados na atividade, não forneceram resposta. A falta de resposta por todos os estudantes nos chamou a atenção, possivelmente, evidenciando (i) a falta de conhecimento ou habilidade em relacionar os fatos observados e os modelos de átomos desenhados (indiretamente, 9 estudantes associaram a organização dos elementos químicos com o modelo atômico de Bohr, ao usar esse modelo para representar os elementos $\mathrm{Li}, \mathrm{Na}, \mathrm{K}$ - Figura 4) a uma ou outra teoria atômica e (ii) falta de interesse ou período curto para resposta de toda a atividade.

\section{CONSIDERAÇÕES FINAIS}

Foi possível perceber que os estudantes, mesmo alguns já tendo contato com os recursos da informática e internet há alguns anos, ainda apresentam dificuldades para a sua utilização no processo de ensino-aprendizagem. Exemplos dessas dificuldades são evidenciados quando os estudantes respondem toda (ou parte significativa) da atividade à mão e posteriormente digitalizam as respostas, fornecendo apenas uma imagem do que foi feito com uma caneta e papel. Outra dificuldade relatada por um estudante se relaciona ao acesso à internet e à plataforma Moodle, dentro do prazo estipulado pelo professor, observe o trecho a seguir.

“... já estamos com alguns dias sem sinal de internet, aqui na minha cidade, e tenho que me deslocar para outra cidade para usá-la. Posso te enviar as resposta da atividade por e-mail?" (Estudante U)

A dificuldade encontrada pelo Estudante U, para acessar a internet, também é compartilhada por outros estudantes do curso de Ciências Biológicas, semipresencial, da UFT. Essa dificuldade é principalmente relacionada ao fato de alguns desses estudantes residirem em cidades extremamente pequenas, no interior do Estado do Tocantins (e afastadas da capital), onde muitas vezes não há nem mesmo rede de energia elétrica.

Ao analisar as respostas fornecidas pelos estudantes a cada uma das questões da atividade, observou-se um número significativo daqueles que não responderam ou apresentaram dificuldades no desenvolvimento da resposta esperada. Isso ficou evidente quando 9 estudantes (41\%), embora soubessem o que é periódico, não conseguiram utilizar o conceito para explicar e diferenciar a variação da massa ou raio atômico com o número atômico dos elementos.

Essas e outras dificuldades provavelmente estão associadas a uma Educação Básica deficiente, que alguns estudantes tiveram, no interior do Estado do Tocantins, pois em várias cidades faltam professores com formação em química.

No Estado do Tocantins, há apenas dois cursos de Licenciatura em Química, sendo um presencial (que se iniciou no $2^{\circ}$ semestre de 2009) e o outro a distância (que se iniciou no $2^{\circ}$ semestre de 2010), ambos na UFT, para formação de professores de Ensino Médio.

\section{REFERÊNCIAS}

1. Tolentino, M.; Rocha-Filho, R. C.; Quim. Nova 1997, 20, 103.

2. Caruso, F.; Oguri, V.; Quim. Nova 1997, 20, 324.

3. Galagovsky, L.; Giacomo, M. A.; Castelo, V.; Rev. Eletr. Ens. Cienc. 2009, 8, 1.

4. Fernandes, C.; Marcondes, M. E. R.; Química Nova na Escola 2006, 24, 20.

5. Driver, R.; Asoko, H.; Leach, J.; Mortimer, E. F.; Scott, P.; Química Nova na Escola 1999, 9, 31.

6. Souza, K. A. F. D.; Cardoso, A. A.; Química Nova na Escola 2008, 27, 51.

7. Bettio, R. W.; Martins, A.; http://www.universia.com.br/materia/materia. jsp?id=5938, acessada em Setembro 2012.

8. Mortimer, E. F.; Machado, A. H.; Química para o ensino médio, $1^{\mathrm{a}}$ ed., Scipione: São Paulo, 2002.

9. Eichler, M.; Del Pino, J. C.; Quim. Nova 2000, 23, 835.

10. Maia, P. F.; Justi, R.; Ensaio Pesq. Educ. Cienc. 2004, 6, 1.

11. Johnstone, A. H.; Chem. Educ. Res. Pract. 2000, 1, 9.

\section{NOTAS}

1. Os trechos transcritos não foram editados, ou seja, os erros, se existirem, permanecem na escrita.

2. O software QuipTabela pode ser encontrado no endereço: http://www.qui.ufmg.br/ quipad/ino/programas/quipta4.01-full.exe. 